\title{
Russian Students' Secular \\ Conceptions of Life Calling: A Qualitative Analysis
}

\author{
Polina M. Beloborodova ${ }^{*}$ Dmitry A. Leontiev \\ National Research University Higher School of Economics, Moscow, Russia \\ *Corresponding author. E-mail: polina.beloborodova@gmail.com
}

Background. During the last decade, life calling has become an areas of dynamically developing research in psychology, management, and counseling. However, it has not been empirically investigated in Russia, despite Russia's rich intellectual and spiritual tradition, and abundant research on related constructs, such as personal meaning.

Objective. The aim of the present study is an initial qualitative exploration of the concept of calling in Russian culture.

Design. We employed qualitative document analysis to examine openended responses from 104 college students regarding their definition of calling, and the actions they undertook to discern and implement that calling.

Results. We found that the students saw a calling as something more than a mere job; were intrinsically motivated to find and dedicate themselves to it; associated a calling with the use of their abilities; and at the same time expected it to make them more energized and successful without considerable effort. While some participants felt called to a specific domain, the majority indicated abstract other or self-oriented callings. Regarding the implementation of their calling, the participants fell into two groups: those who did something specific, such as study and practice, and those who did something vague, such as "everything" or "nothing".

Conclusion. These results are largely in line with similar findings in other cultures. The results can be used in career guidance in educational institutions, as well as in private counseling. Specific recommendations for practice, as well as directions for future research, are explored.

\section{Keywords:}

calling; vocation; career guidance; Russian culture; qualitative document analysis 


\section{Introduction}

Life calling is a rapidly developing area of research in positive and vocational psychology, as well as in management and counseling. To date, the phenomenon of calling has been empirically investigated mostly in the United States and Europe. More than once scholars have pointed out the need for more research with nonWestern subjects (e.g. Hagmaier \& Abele, 2012; Duffy \& Dik, 2013). The existing studies point out that although calling seems to be salient in non-Western cultures, its manifestations are somewhat different (Douglass, Duffy, \& Autin, 2016), and extant measurement instruments show only partial validity (Autin, Allan, Palaniappan, \& Duffy, 2017). Thus, more research on the construct of calling in nonWestern cultures is needed for better understanding of this phenomenon. Also, a more thorough exploration of students' concept of calling is needed, given its significant role in the process of identity formation, and of exploring and identifying with alternative values, lifestyles, friends and partners, social groups, and occupations (LaGuardia \& Ryan, 2002; Marcia \& Archer, 1993).

Studying the nature of calling in Russian culture may bring fruitful results because Russian culture differs from both Western and Eastern cultures. The idea of calling permeates Russian culture on multiple levels and finds expression in Russian Orthodoxy, as well as in Russian philosophy, literature, and people's everyday lives. However, there has to date been no research, to our knowledge, which empirically explored the concept of calling in Russia. Hence employing qualitative methods seems appropriate for the initial examination of this phenomenon.

In this initial qualitative study, we explored secular conceptions of calling in students from two major Russian universities. In the first section of this paper, we summarize the key findings of studies on calling carried out with Western subjects. Then we review the research on calling in non-Western cultures, and finally move to the concept of calling in Russian culture and how it has changed throughout Russian history. Finally, we present our findings and discuss their implications for education and counseling practice, as well as the direction of further research.

\section{Research on calling in the West}

The phenomenon of calling has been studied chiefly among Western populations. Multiple studies show that calling is related to various measures of well-being in different populations, such as work and life satisfaction (Wrzesniewski, McCauley, Rozin, \& Schwartz, 1997; Peterson, Park, Hall, \& Seligman, 2009); meaning in life (Duffy \& Sedlacek, 2010); and self-efficacy (Dik, Sargent, \& Steger, 2008; Domene, 2012). The body of research continues to grow, but there is still a lack of agreement regarding the very definition of calling. As noted in studies by Baumeister (1991) and Elangovan, Pinder, and McLean (2010), the classical conceptualization of calling ("vocation," from the Latin vocare, to call), which stemmed from religion and was grounded in the notions of destiny and moral duty, has evolved into its modern conceptualization, which is focused on self-actualization and personal passion.

Currently there are several related constructs and corresponding measurement scales. They can be broadly divided into those focused on callings in specific areas of work and career, and those defining calling in a more general sense, reaching into other areas of life. 
The first group includes the majority of the concepts and stems from the pioneering study by Bellah, Madsen, Sullivan, Swidler, and Tipton (1985), which was further developed by Wrzesniewski, at al. (1997). Another approach, developed by Hagmaier and Abele (2012), is also focused on work. Praskova, Creed, and Hood (2015) narrowed the focus even further, limiting their concept of calling not only to the work domain, but also to the period of emerging adulthood. Dreher, Holloway, and Schoenfelder (2007) approached calling in a somewhat broader sense, so as to include not only paid work, but also studies, personal projects, and problems, as well as the general experience of daily life.

Concepts in the second group expand the idea of calling beyond the work domain. Dobrow and Tosti-Kharas define it as a consuming, meaningful passion people experience toward a domain (Dobrow \& Tosti-Kharas, 2011, p. 1005), with domains ranging from work, volunteering, and family to more abstract concepts like "social justice." Dik and Duffy (2009) initially defined calling more broadly, but later proposed a new definition which focuses specifically on the work domain (Duffy \& Dik, 2013).

To date, relatively few studies have used qualitative methods to investigate the nature of calling and its implications for work and life. Bunderson and Thompson (2009) in their study on a sample of zookeepers found out that their sense of calling, on the one hand, cultivated a strong professional identification and a sense of meaning and importance, and on the other hand, led to an increased sense of duty, personal sacrifice, and vigilance. In another study, Duffy et al. (2012) interviewed counseling psychologists who perceived their work as a calling. They understood calling as their purpose in life, closely tied to helping or serving others.

While those two studies used adult samples, there have also been several qualitative studies on calling among students. French and Domene (2010) interviewed Canadian Christian female university students and elicited five main themes associated with calling: 1) altruistic focus; 2) intensity; 3 ) deep passion for the domain of the calling; 4) facilitation of others discovering their calling; and 5) the burdens of having a calling. Another study, conducted by Hunter, Dik, and Banning (2010) via an online survey in the United States, found that the participants considered their calling to have stemmed from a guiding force, and to be associated with a higher sense of eudaimonic well-being and job fit.

\section{Research on calling in non-Western cultures}

Research on calling in non-Western populations has just begun. Two quantitative cross-cultural studies involving working adults from the United States and India were aimed at comparing their experience of calling (Douglass et al., 2016), and testing the cross-cultural validity of measurement instruments (Autin et al., 2017). The results of the latter (Autin et al., 2017) put into question the equivalence of the measurements of calling in different cultures and the validity of cross-cultural comparisons.

In light of those findings, qualitative studies may be a good starting point for exploring cultural differences in the manifestation of calling. One such study has been conducted in India on a sample of junior doctors and interns (Nath, 2017). It was found that a sense of calling before entering the medical profession evolved through a family legacy, an emotional response to significant life episodes, and a sense of destiny or direction by a higher power. Another qualitative study was car- 
ried out in China (Zhang, Dik, Wei, \& Zhang, 2015) on a sample of college students, with the aim of exploring their perception of the concept of calling. The most prevalent theme was that calling was a guiding force which manifested itself primarily in a sense of duty. Another theme was associating calling with one's meaning in life, values, and fulfilling purpose.

An additional qualitative study was conducted in Korea among working adults in various fields (Kwon \& Kim, 2014). This study revealed a cognitive component (perceiving a calling) which included having a mission, seeing work as a source of value and goals, and being motivated by contribution and devotion; and a behavioral component (living a calling) which manifested itself in taking responsibility, altruistic behavior, feeling passion for and being absorbed by work, and having a sense of gratification.

As noted by Autin et al. (2017, p. 11), "calling may be a viable construct to examine in other non-Western cultures." It is, of course, premature to draw conclusions about the manifestations of calling in non-Western cultures. But it seems that, regardless of cultural context, calling is grounded in a sense of meaning and passion for one's occupation, and is linked with altruistic behaviors and a sense of positive well-being at work, as well as in other domains and life at large. In the next section we will examine different facets of the phenomenon of calling in Russian culture.

\section{The idea of calling in Russian culture}

The idea of calling in Russian culture (prizvanie in Russian) is rooted in Orthodox Christianity, and manifests itself on three interconnected levels: a universal human calling, the messianic calling of the Russian people, and a personal occupational calling. The notion of a universal human calling in Orthodox Christianity lies in the gradual deification, or accommodation, of man to God, in Whose image he was created, through virtue (Lossky, 1978). Achieving this goal is possible only within the church and the community, for "only if he loves his neighbor can a person be deified" (Ware, 1993, p. 230).

The idea of the messianic calling of the Russian people took shape in the course of the historical development of Russia, as a consequence of recurring episodes of suffering, with the hope for redemption. It was further reinforced by Russia becoming the center of Orthodox Christianity after the fall of Byzantium, and the emergence of the doctrine of Moscow as the Third Rome in the $16^{\text {th }}$ century (Duncan, 2002).

Calling in Russian culture also bears an occupational meaning, emerging from Orthodoxy, and further influenced by major societal and economic transformations in the course of Russian history. In the literature of the Tsarist period, occupational calling was conceptualized as following one's "inner voice," the gradual development of occupational identity, or the pursuit of the civic duty and serving people through work (Klimov \& Noskova, 1992). In the Soviet Union, work was glorified, and the idea of "communist labor" (work as the prime inner need of each person and an end in itself) was promoted through various media. Throughout the turbulent decade following the collapse of the Soviet Union, when economic survival was in question for a large share of the population, work continued to be a central value, with "guaranteed work" the main desired outcome (Khakhulina, 2008). Then, as economic stability increased in the 2000s, some people, especially 
the younger generation, shifted their attention to other interests, such as family and friends (Ardichvili, 2009).

In recent years the idea of occupational calling seems to have again attracted interest. A range of self-help books on the topic have been published, mostly during the last five years. Also, many in-class and online courses aimed at helping people find their callings have been created. Unfortunately, all those initiatives are not supported by research and are based mainly on their authors' personal experience. No research in Russia, to our knowledge, has specifically addressed the phenomenon of calling and examined it empirically, despite Russia's long intellectual and spiritual tradition and extensive research on related constructs, such as personal meaning (Leontiev, 2013). In the following sections we expound on the findings from our survey of students from two major Russian universities about their secular concepts of calling.

\section{Methods}

The aim of the present study is an initial exploration of the phenomenon of calling in Russian culture. Since calling has not been empirically examined previously, an inductive qualitative approach has been chosen.

Our data were collected via an online survey taken by 104 students from two top Russian universities: 51 students from the National Research University Higher School of Economics (hereafter referred to as HSE) and 53 students from the National Research Nuclear University MEPhI (hereafter MEPhI). HSE students completed the questionnaire as part of a career guidance elective course; MEPhI students completed it during an introductory psychology elective course. Participation in the survey was anonymous and voluntary; the participants did not receive credit or other incentives. The mean age was 18.9 years $(S D=1.6$; range $=17-31)$. The majority of respondents self-identified as female $(N=81 ; 77.9 \%)$. The HSE sample was more heterogeneous (mean age was 20.4 years; $S D=1.64$; range $=17-31$, six fields of study), whereas the MEPhI sample was more homogeneous (mean age 17.5 years; $S D=0.52$; range $=17-19$, one field of study). This was due to the fact that the course at HSE was available to all students, whereas the course at MEPhI was designed for first year students of one academic program.

The questionnaire included both open-ended and closed questions. The closed questions ("Do you have a calling in your life?", "Do you know people who have a calling?", "Are you searching for your calling?") were included in order to lead the respondents to answer appropriate open-ended questions through the online form, depending upon whether they were searching for a calling, or had already found one We were interested in both cognitive and behavioral components, i.e. how students defined calling, and what actions they undertook to discern and implement it.

The questionnaire was completed by a total of 126 students. One hundred four (104) of them (83.2\% in total: $79.7 \%$ in HSE and $85.5 \%$ in MEPhI) indicated that calling was a relevant concept for them by giving a positive answer to at least one of the closed questions. Those respondents were further asked to define calling as they understood it. The majority of the respondents $(71.1 \%)$ indicated that they did not have a calling, but knew people who did. Almost all of them were also searching for a calling, and were asked what they were doing to find it. The remaining 
$28.9 \%$ of the respondents indicated that they had a calling, and were asked what it was and what they did to actualize it in their lives. The relationship between the sense of having a calling and the participants' gender was insignificant, according to the Chi-square Test $\left(\chi^{2}=1.52 ; d f=1 ; p>0.05\right)$. However, the sense of having a calling was significantly related to age, according to one-way ANOVA (Welch's $F(1,65.82)=4.41 ; p<.05)$. As indicated by the Games-Howell post hoc test, the mean age of students with callings $(M=19 ; S D=5.4)$ was significantly higher than the mean age of students who indicated that they did not have a calling $(M=18$; $S D=3.6)$ at $p<.05$.

The open-ended questions were analyzed using qualitative document analysis (Altheide, Coyle, DeVriese, \& Schneider, 2008). This procedure means that instead of using predefined categories, the researchers derive them inductively from the data. Such an inductive approach is appropriate for working with phenomena about which there is limited prior knowledge (Elo \& Kyngäs, 2008), which is the case for the concept of calling in Russian culture. Furthermore, in previous qualitative studies of students' conceptualizations of calling (Hunter et al., 2010; Zhang, Dik. et al., 2015), the same method was employed, and thus its use would allow comparison of the results.

First, the answers to the open-ended questions were independently coded by both authors and a third expert, using the procedure of initial coding (Saldaña, 2015). The answers were split into discrete blocks which were closely examined and assigned descriptive labels summarizing their meaning. Previously coded answers could be re-coded, if labels which later emerged from the data seemed to convey the meaning better. This process continued until a saturation level was reached, which suggested that no new labels could be derived from the data. In order to reach inter-coder consensus, the coders met to compare and discuss the labels. As a result, some of the labels were renamed and redefined, and a final list was created. An analytic memo, laying out the labels, their descriptions, and examples of answers, was written to prepare for the next stage of the analysis, axial coding. Its goal was to develop categories, or themes, representing several labels. Each label could be used in more than one theme. The researchers initially went through this process individually, and then met to discuss the results and adjust the themes to better reflect the labels' meanings. The themes were subsequently described in an analytic memo which served as the basis for the present paper.

\section{Results}

\section{Definition of calling}

The responses to the question, "What do you mean by calling, how would you define it?" were coded by 15 labels which subsequently formed six themes: Intrinsic Motivation; Success; More than a Job; Dedication; Abilities; and Energy Influx. As shown in Table 1, the theme Intrinsic Motivation reflects the labels which point to an internal impulse to engage in an activity for its own sake, finding it personally rewarding and enjoyable, and perceiving a fit between oneself and an occupation. Respondents also often referred to attaining a desired result or getting positive feedback, often without considerable effort, as an indicator of calling, which is reflected in the theme Success. 
The next theme, More than a Job, amalgamates answers which suggest seeing one's current or future occupation as meaningful and worthy of dedicating one's life to. The theme Dedication means readiness to commit resources and bring benefit to others, even without material reward. The respondents also frequently mentioned abilities in a particular area, inborn or cultivated, which was reflected in the theme Abilities. Finally, several participants mentioned becoming more energized by, rather than weary of, calling-related activities, which constituted the theme Energy Influx. The majority of the responses reflected more than one theme, as can be observed in the examples in Table 1.

Table 1

Definition of calling: themes, labels, and examples

\section{Intrinsic motivation}

Positive affect. Participant 43: "Ability to do something and enjoy the process"

Interest. Participant 18: "Passion, being sick with something (in a good sense), when your eyes are glowing as you are talking about this subject"

Urge. Participant 3: "Something, that a person would like to do, where she actualizes the strengths that she mastered, and which she is best at"

Fit. Participant 74: "When a person occupies her niche, finds something she would like to specialize in"

\section{Success}

Successful performance. Participant 21: "Something you are successful at more than others, while spending the same amount of resources"

Ease. Participant 52: "You like what you do, and you don't have to exert titanic efforts to master it"

\section{More than a Job}

Purpose. Participant 22: "Something that a person constructs her existence for, her personal life mission"

Self-realization. Participant 60: "Calling is an occupation in which a person can actualize herself, realize her potential and make a contribution to society"

Lifetime project. Participant 118: "It is something that a person is willing to dedicate her whole life to"

Contribution. Participant 125: “A person's goal, her contribution to the development of the mankind"

\section{Dedication}

Unselfishness. Participant 25: "Calling is a kind of work that you love and are ready to carry on without monetary incentives"

Contribution. Participant 125: "A person's goal, her contribution to the development of mankind"

Investing resources. Participant 16: "An occupation in which a person can invest her resources totally, and which she enjoys"

\footnotetext{
Abilities

Competences. Participant 14: "Developed talents and interest in the profession"

Giftedness. Participant 73: "It is that 'handicraft' which comes easily by itself; it is given by nature, when you live and breathe it"

\section{Energy Influx}

Energy influx. Participant 49: "To engage in something which brings energy, an occupation that makes you feel fulfilled, which makes the world a better place"
}

Note. Themes are in bold, labels are in italic. In the examples of responses, the pronouns are used according to the participants' gender. 


\section{Activities toward discernment of calling}

The majority of the participants indicated that they were searching for a calling. They were further asked to describe what actions they undertook to discern it. Their responses were grouped into two themes (Behavior and Processing), which included the majority of the answers, and a less prominent third theme, Nonspecific. The themes Behavior and Processing reflected two sides of searching for a calling: 1) observable activity aimed at exploring different domains, and 2) the internal activity of reflecting on one's experiences and self-development. The third theme, Nonspecific, included answers in which actions were not clearly articulated (for example, Participant 99 wrote, "Simply living and observing"), or were non-existent. See Table 2 for more examples of participants' responses.

\section{Table 2}

Activities to discern one's calling: themes, labels, and examples

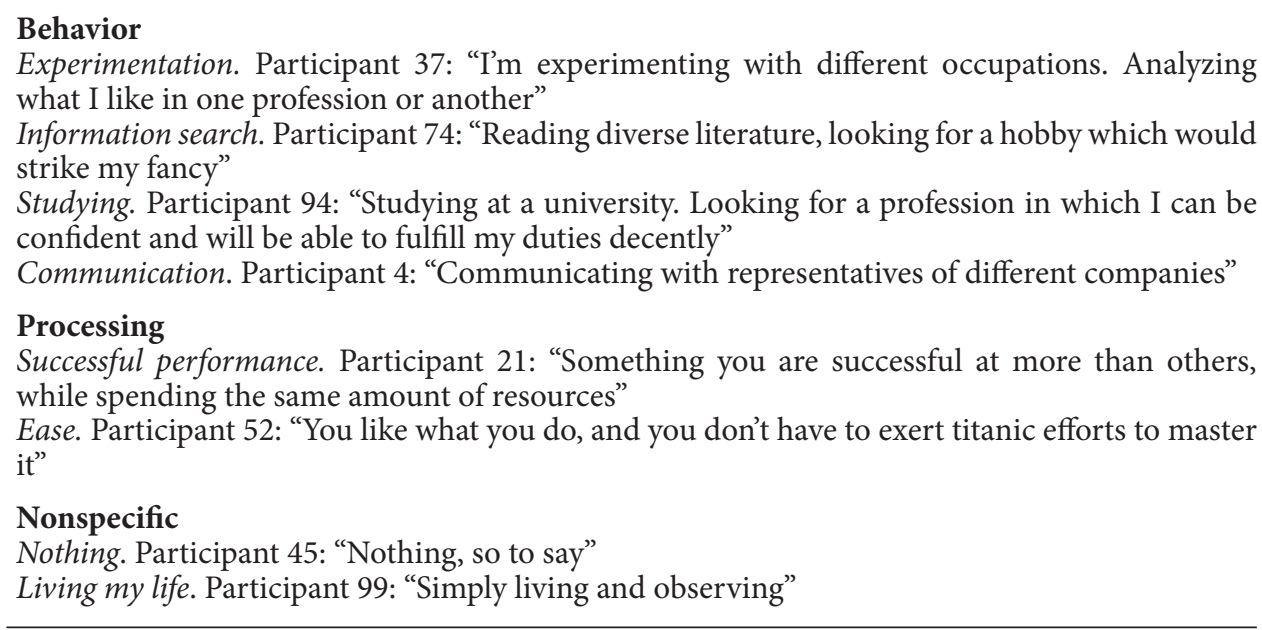

Note. Themes are in bold, labels are in italic.

\section{The content of a calling}

The participants who indicated that they had a calling, were asked what their callings were. Out of 10 labels assigned to the responses, four themes emerged: 1) Specific Domain; 2) Other-oriented Calling; 3) Self-oriented Calling; and 4) I Don't Know, as shown in Table 3. Only 10\% of the total number of the respondents indicated a particular profession, subject, or life role, which could be reflected in the theme Specific Domain. The majority of the respondents mentioned abstract otheroriented callings, such as contributing and helping others, or equally abstract selforiented callings, such as self-development, independence, and happiness. Otheroriented callings were much more widespread than self-oriented callings, with the most frequently coded labels being Contribution and Helping. Finally, some of the respondents said that they did not know what their calling was. 
Table 3

Content of calling: themes, labels, and examples

\section{Specific Domain}

Specific subject. Participant 91: "I found my calling in sport dance"

Family. Participant 102: "I'm the eldest in my family"

\section{Other-oriented Calling}

Contribution. Participant 33: "To be helpful to the society and assist people whenever possible" Helping. Participant 125: "To solve the society's current real-life challenges. To give positive emotions with my very existence and actions, help people by virtue of my abilities"

Beneficial communication. Participant 15: "In communication with benefit"

Family. Participant 102: "I'm the eldest in my family"

\section{Self-oriented Calling}

Self-development. Participant 77: "In constant self-development"

Independence. Participant 122: "One strives to gain a foothold in life"

Fulfil one's predestination. Participant 52: "To fulfill my predestination in life"

Happiness. Participant 123: "To be happy"

\section{Don't Know}

I don't know. Participant 34: "I don't know yet what it is, but I'm sure it exists"

Note. Themes are in bold, labels are in italic.

\section{Activities for implementation of calling}

In addition to describing their callings, participants who indicated that they had a calling were asked to describe their activities directed at its implementation. Their responses were coded with seven labels, which were converted into two themes: Doing Something and Doing Everything/Nothing. The first theme reflected a broad scope of specific activities aimed at pursuing a calling, which could not be meaningfully divided into smaller groups. The second theme included responses indicating broad uninformative actions such as "nothing" and "everything". See Table 4 for examples of participants' responses.

Table 4

Activities for implementation of calling: themes, labels, and examples

\footnotetext{
Doing Something provides"

Practicing. Participant 104: "I'm photographing and taking interest in psychology"

Development. Participant 91: "I'm exercising persistently and perfecting my skills"

Communication. Participant 15: "I’m widening my social circle" like something, I try to do it more and wholly give myself to it"

\section{Doing Everything/Nothing}

Nothing. Participant 39: "As yet, nothing"

Everything to be happy. Participant 123: "Things that make me happy"
}

Learning. Participant 33: "I'm trying to absorb the most useful knowledge which the university

Search. Participant 121: "I didn't make up my mind yet; I'm studying and trying everything. If I

Note. Themes are in bold, labels are in italic. 


\section{Discussion}

The purpose of the present study was to examine Russian students' secular conceptions of calling, including both cognitive and behavioral components, i.e. their definitions of calling, and actions they undertook to discern and actualize that calling. Some of our findings seem to correspond to previous research, and some are rather surprising.

In a qualitative analysis of the responses to the open-ended question about the definition of calling, we identified six main themes: Intrinsic Motivation, Success, More than a Job, Dedication, Abilities, and Energy Influx. The most prominent theme Intrinsic Motivation reflects interest and an urge towards a calling domain, as well as a sense of fit and positive affect. This outcome echoes Dreher et al's (2007) view of calling as an intrinsically motivated occupation imbued with significance and joy. Wrzesniewski et al. (1997) also refer to calling as an end in itself, as opposed to the other two work-related orientations, job and career, which serve as means to other ends (monetary rewards and career advancement).

It is notable that positive affect was the most frequently coded label, and no negative aspect, such as burden or sacrifice, was ever mentioned by participants in the present sample. This might be due to their lack of experience of living a calling; the majority of the respondents indicated that they had not found their callings yet. It is also possible that such unrealistic expectations are created by popular literature on calling currently circulating in Russia. The authors of such literature often promote calling as an occupation that, once found, automatically and inevitably brings enjoyment and success. This might be one of the reasons why the next theme that we identified, Success, was so frequently referred to as an indicator of calling, which was not characteristic of American and Chinese samples in similar studies (Hunter et al., 2010; Zhang, Dik, et al., 2015). This finding could indicate that for Russian students, "career" work orientation (as conceptualized by Wrzesniewski et al., 1997) is so strong that it merges with their concept of calling.

The third theme, More than a Job, expresses the tendency to see one's occupation as a source of self-realization and a personally meaningful project which can potentially span one's whole life. It is congruent with a large body of research linking the concept of calling to meaning in life (e.g., Dik et al., 2008; Duffy \& Sedlacek, 2010). The next theme, Dedication, reflects the desire to give: invest resources and contribute to the other people's well-being. This theme is less pronounced in our findings regarding the definition of calling, but it frequently appears in the responses to the question about the content of calling. The majority of the respondents mentioned other-oriented callings such as contributing and helping, rather than self-oriented callings, such as self-development and happiness. This outcome is in line with the view of Russian culture as being "in-between" West and East in terms of the individualism/collectivism dimension (Latova \& Latov, 2008), and provides evidence for Dik and Duffy's (2009) hypothesis that in individualistic cultures, personal meaning could be more salient, and in collectivistic cultures, social contributions could play a larger role in the conceptualization of calling.

The next theme, Abilities, was less prominent, but still noticeable. It emerged from responses stating that having a calling provides opportunities for one to employ one's inborn or cultivated abilities. This resonates with Bunderson and Thom- 
son's (2009) study, as well as research by Harzer and Ruch (2012) which associates calling with the use of signature strengths. It is also noteworthy that using strengths and abilities was mentioned by the respondents in an analogous study in the United States (Hunter et al., 2010), but not in China (Zhang, Dik, et al., 2015), a result which provides additional evidence for the above-mentioned notion about the influence of the individualism/collectivism dimension on the concept of calling in this Russian sample. The final theme, Energy Influx, amalgamated the idea of deriving energy from calling-related activities, rather than spending it. This outcome echoes a finding that zestful individuals tended to approach their work as a calling (Peterson et al., 2009).

One striking difference in our findings from the analogous studies in the United States and China (Hunter et al., 2010; Zhang, Dik, et al., 2015) is that Russian respondents did not refer to a guiding force, such as God, destiny, society, or family, as a source of calling. The closest idea to that was a sense of mission and purpose from an amorphous source. The lack of religious or spiritual references showcases an inclination to a more secular concept of calling, which could be a result of secularization caused by a long period of atheistic communism, as well as the global tendency toward secularization.

Our analysis of the responses to the question about the activities involved in the discernment of calling elicited three themes: Behavior, Processing, and Nonspecific. The first two themes involved experimentation with different domains, followed by self-reflection. Similar findings were reported in qualitative studies on samples of working adults with callings. The discovery of calling was facilitated by exposure to a calling domain (Duffy et al., 2012) and involved trying out different professions (French \& Domene, 2010). Dobrow (2013) also pointed out that behavioral involvement with different domains furthers the development of a calling through a process of testing out different provisional selves. The majority of the respondents were actively engaged in their search for calling; however, a small share indicated that they were not doing anything at the moment, or were just "living their lives;" these responses were included under the theme Nonspecific.

We were also interested in the actual content of the callings of those participants who indicated that they had one. Four themes were identified: Specific Domain, Other-oriented Calling, Self-oriented Calling, and I Don't Know. Only a handful of the respondents provided a specific domain, such as mathematics or sport dance. The majority described their callings in abstract terms or indicated that they did not know what their calling was. This result provides additional evidence to support the notion that calling can be experienced towards a wide spectrum of domains, from a specific occupation to an abstract cause or life in general. This view is supported by a number of scholars who define calling as a life role (Dik \& Duffy, 2009), a meaningful passion towards a domain (Dobrow \& Tosti-Kharas, 2011), and the experience of joy and meaning in work and daily life (Dreher et al., 2007). We also asked the respondents how they implemented their callings in their lives. The analysis produced two themes: Doing Something, or active behavioral involvement with the calling domain, and Doing Everything/Nothing, or the lack of specific actions. The majority of the respondents reported such activities as practicing, studying, development, and communication. 


\section{Conclusion}

Overall our findings on the concept of calling in Russia converge with previous research results on calling in Western and non-Western samples on the following key points: 1) calling is a salient concept for Russian culture; 2) a sense of calling is grounded in personal meaning and other-oriented motivation, and is related to positive affect; 3) calling spans areas ranging from a specific occupation, domain, or life role to general life experience; and 4) the discernment of calling requires experimentation with different domains followed by self-reflection. Further exploration involving larger and more diverse samples is needed to better understand such outcomes as the students' expectation of entirely positive experience and success without considerable effort once a calling is found, as well as the lack of references to a guiding force as a source of calling.

The results of the present study can be used in career guidance in educational institutions, as well as in private counseling. Although Russia has a long tradition of vocational guidance dating back to the 1920 s, it was (and still is) provided mostly at the high school level. Although a few universities have career planning centers, the majority of them rely on counseling and psychological services which are focused mainly on other psychological issues (Watts \& Zabrodin, 2003). In this light university career guidance practices in Russia can include exploration of the concept of calling from the beginning, which is more convenient than integrating it into existing practices. As for private counseling, as it is understood in the West, it is just starting to emerge in Russia as a branch of social work (Currie, Kuzmina, \& Nadyuk, 2012). Furthermore, the existing practices of career counseling in Russia at the school level and beyond are focused on abilities and skills rather than on personality and motivation.

The idea of calling and its discernment shifts the emphasis from aptitudes to personality, and makes personal preferences and values (i.e., motivation, broadly speaking) the most important aspect of this process. This is in line with the idea of choice readiness, which suggests that not every individual is capable of making a responsible personal choice that he or she would not later regret; what matters is the way one makes the choice rather that what one chooses, and most appropriate interventions consist in developing this general capacity for making decisions (Leontiev, Rasskazova, Fam, \& Ovchinnikova, 2016). We further elaborate below on specific points that counselors may discuss with clients, and challenges that may be encountered in the counseling process. For convenience, we refer to both private counselors' clients and students who receive career guidance as "clients."

If the idea of calling is relevant for the client, it is important to discuss how the client defines it and to adjust the counseling process accordingly. Possible questions to explore with the client are his/her sources of positive emotions, abilities and signature strengths, values system, and ways of contributing to others' lives. As a result of this process, a broad understanding of possible callings may emerge. At this point, because the research suggests that experimentation and exposure to different domains is crucial in discerning one's calling, it is important to lead the client to look for concrete opportunities to engage with possible callings. Research results suggest that calling may be experienced in a variety of domains; hence it is advisable to look for opportunities in a professional setting, volunteering, education, leisure, personal life, and others. 
Our findings also point to challenges that can be encountered in counseling work on calling, namely the client's expectation of success without considerable effort, and lack of awareness of the negative aspects of calling. In view of this, it is advisable to introduce the client to a more realistic picture of what it means to have and live a calling, and discuss challenges that may arise on the way toward discerning and implementing one's calling, as well as ways to mitigate those challenges.

\section{Limitations}

The results of the present study provide important insights into the concept of calling in Russian culture; nevertheless, its limitations call for further research in a number of directions. A major limitation often encountered in qualitative research is a restricted sample. Our sample was comprised of students from two highly competitive universities who chose psychology-related elective courses, which could point to a systematic difference between them and students who do not exhibit interest in psychology and study in the other universities. Hence research with a more diverse sample, including from universities located in different regions of Russia, is needed to find out whether our findings are characteristic of the larger population of Russian students.

Also, as indicated by Hunter et al. (2010) and Zhang, Dik, et al. (2015), although college students are a good starting point for the exploration of the construct of calling, given the role calling can play in identity formation, further research should include working adults with more work and life experience and varying levels of education, who could present a different perspective on calling.

Finally, all participants who indicated that calling was a relevant idea for them were included in the study, regardless of the intensity of their connection with this concept. As noted by Hunter et al. (2010), the depth of this connection may influence the conceptualizations of calling and should be accounted for in future research. Because of these limitations, the comparison of the concept of calling in Russian culture based on our findings with concepts of calling in other cultures is possible, but needs to be done with caution.

\section{Acknowledgements}

This research has been funded by the Russian Foundation for Basic Research, project 17-06-01009, "Personality development through the transition from childhood to adulthood: psychological mechanisms, indicators and trajectories." The authors are grateful to Dr. Dmitry Suchkov for granting his time and expertise to participate in the data analysis procedures.

\section{References}

Altheide, D., Coyle, M., DeVriese, K., \& Schneider, C. (2008). Emergent qualitative document analysis. In Hesse-Biber, S. \& Leavy, P. (Eds.), Handbook of emergent methods (pp. 127-151). New York: Guilford Press.

Ardichvili, A. (2009). The relationship between meaning of working and socioeconomic transformations: The case of post-communist Russia. Advances in Developing Human Resources, 11(2), 218-234. https://doi.org/10.1177/1523422309332244 
Autin, K.L., Allan, B.A., Palaniappan, M., \& Duffy, R.D. (2017). Career calling in India and the United States: A cross-cultural measurement study. Journal of Career Assessment, 25(4), 688-702. https://doi.org/10.1177/1069072716665860

Baumeister, R.F. (1991). Meanings of life. New York: Guilford Press.

Bellah, R.N., Madsen, R., Sullivan, W.M., Swidler, A., \& Tipton, S.M. (1986). Habits of the heart. New York: Harper \& Row.

Bunderson, J.S., \& Thompson, J.A. (2009). The call of the wild: Zookeepers, callings, and the double-edged sword of deeply meaningful work. Administrative Science Quarterly, 54(1), 32-57. https://doi.org/10.2189/asqu.2009.54.1.32

Currie, C.L., Kuzmina, M.V., \& Nadyuk, R.I. (2012). The counseling profession in Russia: Historical roots, current trends, and future perspectives. Journal of Counseling \& Development, 90(4), 488-493. https://doi.org/10.1002/j.1556-6676.2012.00060.x

Dik, B.J., \& Duffy, R.D. (2009). Calling and vocation at work: Definitions and prospects for research and practice. Counseling Psychologist, 37(3), 625-632. https://doi. org/10.1177/0011000008316430

Dik, B.J., Sargent, A.M., \& Steger, M.F. (2008). Career development strivings: Assessing goals and motivation in career decision-making and planning. Journal of Career Development, 35(1), 23-41. https://doi.org/10.1177/0894845308317934

Dobrow, S.R. (2013). Dynamics of calling: A longitudinal study of musicians. Journal of Organizational Behavior, 34(4), 431-452. https://doi.org/10.1002/job.1808

Dobrow, S.R., \& Tosti-Kharas, J. (2011). Calling: The development of a scale measure. Personnel Psychology, 64(4), 1001-1049. https://doi.org/10.1111/j.1744-6570.2011.01234.x

Domene, J.F. (2012). Calling and career outcome expectations: The mediating role of self- efficacy. Journal of Career Assessment, 20(3), 281-292. https://doi.org/10.1177/1069072711434413

Douglass, R.P., Duffy, R.D., \& Autin, K.L. (2016). Living a calling, nationality, and life satisfaction: A moderated, multiple mediator model. Journal of Career Assessment, 24(2), 253-269. https://doi.org/10.1177/1069072715580324

Dreher, D.E., Holloway, K.A., \& Schoenfelder, E. (2007). The vocation identity questionnaire: Measuring the sense of calling. In Piedmont, R.L. (Ed.), Research in the Social Scientific Study of Religion (Vol. 18, pp. 99-120). https://doi.org/10.1163/ej.9789004158511.i-301.42

Duffy, R.D., \& Dik, B.J. (2013). Research on calling: What have we learned and where are we going? Journal of Vocational Behavior, 83(3), 428-436. https://doi.org/10.1016/j.jvb.2013.06.006

Duffy, R.D., Foley, P.F., Raque-Bodgan, T.L., Reid-Marks, L., Dik, B.J., Castano, M.C., \& Adams, C.M. (2012). Counseling psychologists who view their careers as a calling: A qualitative study. Journal of Career Assessment, 20(3), 293-308. https://doi.org/10.1177/1069072711436145

Duffy, R.D., \& Sedlacek, W.E. (2010). The salience of a career calling among college students: Exploring group differences and links to religiousness, life meaning, and life satisfaction. The Career Development Quarterly, 59(1), 27-41. https://doi.org/10.1002/j.2161-0045.2010. tb00128.x

Duncan, P.J.S. (2002). Russian messianism: Third Rome, revolution, communism and after. Routledge.

Elangovan, A.R., Pinder, C.C., \& McLean, M. (2010). Callings and organizational behavior. Journal of Vocational Behavior, 76(3), 428-440. https://doi.org/10.1016/j.jvb.2009.10.009

Elo, S., \& Kyngäs, H. (2008). The qualitative content analysis process. Journal of Advanced Nursing, 62(1), 107-115. https://doi.org/10.1111/j.1365-2648.2007.04569.x

French, J.R., \& Domene, J.F. (2010). Sense of "calling": An organizing principle for the lives and values of young women in university. Canadian Journal of Counselling and Psychotherapy, $44(1), 1-14$. 
Hagmaier, T., \& Abele, A.E. (2012). The multidimensionality of calling: Conceptualization, measurement and a bicultural perspective. Journal of Vocational Behavior, 81(1), 39-51. https:// doi.org/10.1016/j.jvb.2012.04.001

Harzer, C., \& Ruch, W. (2012). When the job is a calling: The role of applying one's signature strengths at work. Journal of Positive Psychology, 7(5), 362-371. https://doi. org/10.1080/17439760.2012.702784

Hunter, I., Dik, B.J., \& Banning, J.H. (2010). College students' perceptions of calling in work and life: A qualitative analysis. Journal of Vocational Behavior, 76(2), 178-186. https://doi. org/10.1016/j.jvb.2009.10.008

Khakhulina, L. (2008). Work in the system of life orientations of the Russian population. Sociological Research, 47(2), 6-32. https://doi.org/10.2753/SOR1061-0154470201

Klimov, E.A., \& Noskova O.G. (1992). Istoriya psikhologii truda v Rossii. Uchebnoe posobie [The History of Psychology of Labor in Russia. A Handbook]. Moscow: Moscow University Publishing.

Kwon, S., \& Kim, M. (2014). Qualitative study for exploring the construct of vocational calling and the effect of factors on living a calling. Korean Journal of Youth Studies, 21(6), 393-420. Retrieved from http://www.kyra.or.kr

LaGuardia, J.G., \& Ryan, R.M. (2002). What adolescents need: A self-determination theory perspective on development within families, school, and society. In Pajares, F. \& Urdan, T. (Eds.), Academic motivation of adolescents (pp. 193-220). Greenwich, CN: Information Age.

Latova, N., \& Latov, Y. (2008). Etnometricheskie podkhody k sravnitelnomu analizu khozyaistvenno-kulturnykh tsennostei [Ethnometric approaches to comparative analysis of economic and cultural values]. Economic Issues, 5, 80-102. https://doi. org/10.32609/0042-8736-2008-5-80-102

Leontiev, D. (2013). Personal meaning: A challenge for psychology. Journal of Positive Psycho$\log y, 8(6), 459-470$. https://doi.org/10.1080/17439760.2013.830767

Leontiev, D., Rasskazova, E., Fam, A., \& Ovchinnikova, E. (2016). Psikhologia vybora [Psychology of Choice]. Moscow: Smysl.

Lossky, V. (1978). Orthodox theology: An introduction. Trans. by Ian \& Ihita Kesarodi-Watson. Crestwood, NY: St Vladimir's Seminary Press.

Marcia, J.E., \& Archer, S.L. (1993). Identity status in late adolescence: Scoring criteria. In Marcia, J.E., Waterman, A.S., Matteson, D.R., Archer, S.L., \& Orlofsky, J.L. (Eds.), Ego Identity (pp. 205-240). New York: Springer-Verlag. https://doi.org/10.1007/978-1-4613-8330-7_9

Nath, V. (2017). Calling orientations of junior doctors and medical interns in India: Cultural, occupational and relational perspectives. International Journal for Educational and Vocational Guidance, 17(2), 143-163. https://doi.org/10.1007/s10775-016-9321-2

Peterson, C., Park, N., Hall, N., \& Seligman, M.E.P. (2009). Zest and work. Journal of Organizational Behavior, 30, 161-172. https://doi.org/10.1002/job.584

Praskova, A., Creed, P.A., \& Hood, M. (2015). The development and initial validation of a career calling scale for emerging adults. Journal of Career Assessment, 23(1), 91-106. https://doi. org/10.1177/1069072714523089

Saldaña, J. (2015). The coding manual for qualitative researchers. London: Sage.

Ware, T. (1993). The orthodox church: An introduction to eastern Christianity. London: Penguin.

Watts, A.G., \& Zabrodin, Y. (2003). Public policies and career development: A framework for the design of career information, guidance and counseling services in developing and transition countries. Country report on Russia. Washington, DC: The World Bank.

Wrzesniewski, A., McCauley, C., Rozin, P., \& Schwartz, B. (1997). Jobs, careers, and callings: People's relations to their work. Journal of Research in Personality, 31(1), 21-33. https://doi. org/10.1006/jrpe.1997.2162 
Zhang, C., Dik, B.J., Wei, J., \& Zhang, J. (2015). Work as a calling in China: A qualitative study of Chinese college students. Journal of Career Assessment, 23(2), 236-249. https://doi. org/10.1177/1069072714535029

Original manuscript received August 31, 2018

Revised manuscript accepted March 04, 2019

First published online May 30, 2019

To cite this article: Beloborodova, P.M., Leontiev, D.A. (2019). Russian Students' Secular Conceptions of Life Calling: A Qualitative Analysis. Psychology in Russia: State of the Art, 12(2), 3-18. DOI: $10.11621 /$ pir.2019.0201 